\title{
The First Mouse Model of Primary Osteosarcoma of the Breast
}

\author{
NATHANIEL F. WU ${ }^{1,2}$, JUSTIN WU $^{3,4}$, JUN YAMAMOTO ${ }^{1,4}$, YUSUKE AOKI $^{1,4}$, \\ CHIHIRO HOZUMI ${ }^{5}$, MICHAEL BOUVET ${ }^{4}$ and ROBERT M. HOFFMAN ${ }^{1,4}$ \\ ${ }^{1}$ AntiCancer Inc, San Diego, CA, U.S.A.; \\ ${ }^{2}$ Department of Molecular and Cellular Biology, Harvard University, Cambridge, MA, U.S.A.; \\ ${ }^{3}$ Department of General Surgery, Kaiser Permanente San Diego Medical Center, San Diego, CA, U.S.A.; \\ ${ }^{4}$ Department of Surgery, University of California, San Diego, CA, U.S.A.; \\ ${ }^{5}$ AntiCancer Japan Inc, Narita, Japan
}

\begin{abstract}
Background/Aim: Sarcomas of the breast are extremely rare malignant tumors and comprise only $5 \%$ of all sarcomas and fewer than 1\% of breast cancers. Primary osteosarcoma of the breast is histologically indistinguishable from osteosarcoma of the bone. Effective therapies of this recalcitrant disease have not yet been developed. Materials and Methods: A patient-derived xenograft (PDX) mouse model of primary osteosarcoma of the breast was established by subcutaneous implantation of the surgical specimen, along with surrounding normal tissue. Hematoxylin and eosin $(H \& E)$ staining was performed on paraffin-embedded histological sections of the original tumor resected from the patient and from implanted tumors that grew in nude mice. Results: Tumors grew in 46 of 51 mice implanted with the original surgical specimen. The $H \& E$-stained slides of the mouse-grown tumor and the original patient tumor matched, both showing large areas of spindle-shaped cells, characteristic of osteosarcoma. Conclusion: The first PDX mouse model of primary breast osteosarcoma was established which will enable testing of novel therapeutics as well as basic research of osteosarcoma of the breast.
\end{abstract}

Rare tumors currently comprise approximately 200 types. Osteosarcomas of the breast are extremely rare malignant tumors and comprise fewer than 5\% of all sarcomas and fewer than $1 \%$ of breast cancers (1). Histologically, primary osteosarcoma of the breast is indistinguishable from osteosarcoma of the bone (2). Very few primary mammary

This article is freely accessible online.

Correspondence to: Robert M. Hoffman, Ph.D., AntiCancer Inc, 7917 Ostrow St, San Diego, CA, 92111, U.S.A. Tel: +1 8586542555, Fax: +1 8582684175, e-mail: all@anticancer.com

Key Words: Primary osteosarcoma of the breast, rare cancer, PDX, patient-derived xenograft, nude mouse. osteosarcomas have been reported and are among rare extraskeletal osteosarcomas (3). One study by Silver et al. reviewed 50 cases (49 women, 1 man) of pure osteosarcoma of the breast between 1957 and 1995 (3). In 32 cases, there was a confirmed absence of epithelial differentiation. Of the reviewed cases, 11 were local recurrences and 15 developed metastases. Sixteen patients died of the disease. Primary osteosarcomas of the breast are highly aggressive tumors that develop from totipotent mesenchymal cells of the breast stroma or, as previously described, by transformation from a preexisting phyllodes tumor (2). Osteosarcoma of the breast is characterized by early recurrence and a tendency for hematogenous but not lymphatic dissemination. Metastases most commonly occur in the lungs (2). Because of limited data, clinical features and optimal treatment have yet to be defined $(1,4)$.

In 1969, Rygaard was the first to successfully establish a patient-derived xenograft (PDX) model after transplanting and growing surgical colon cancer specimens subcutaneously in nude mice (5). Since then, numerous different cancer types have been established as PDX models. Due to the rare occurrence and limited records of primary osteosarcoma of the breast, a patient-derived xenograft (PDX) mouse model has yet to be established. In the present study, a PDX nude-mouse model was established from a surgical specimen obtained from a patient with osteosarcoma of the breast, using the tumorimplantation method of Hozumi, which involves subcutaneous implantation of tumor, as well as surrounding normal, non-cancerous tissue (5).

\section{Materials and Methods}

Mice. For the establishment of this PDX model of primary osteosarcoma of the breast we used athymic (nu/nu) nude mice (AntiCancer, Inc., San Diego, CA, USA) and followed an AntiCancer, Inc. Institutional Animal Care and Use Committee (IACUC) protocol specifically approved for this study. The present study followed the principles and procedures outlined in the 
A
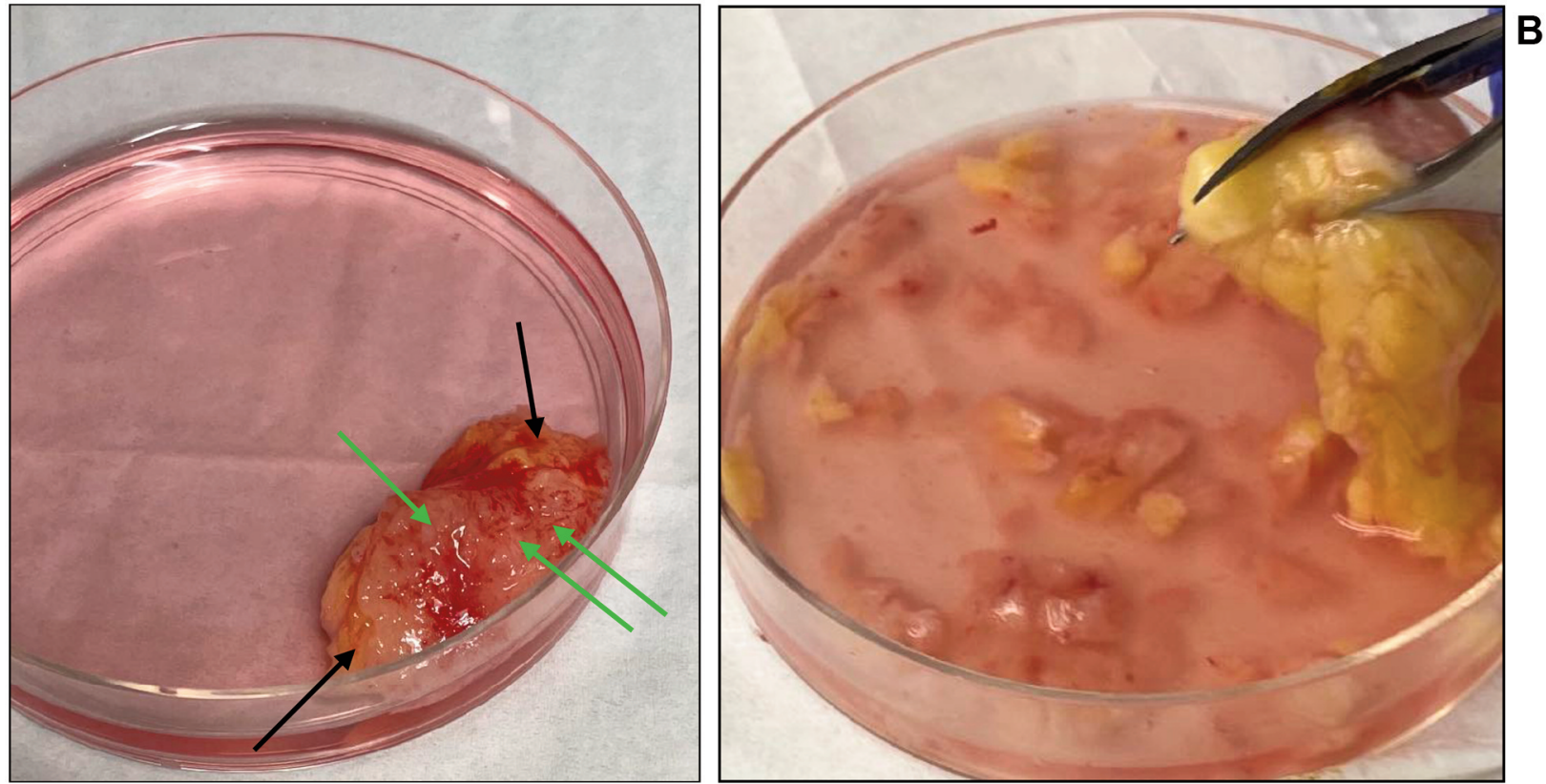

Figure 1. A surgical specimen of primary breast osteosarcoma tissue and surrounding normal tissue before further fragmentation. (A) Green arrows indicate tumor tissue; black arrows indicate surrounding normal tissue. (B) Fragmentation of primary breast osteosarcoma tumor tissue and surrounding normal tissue.

Table I. Establishment frequency of the patient breast osteosarcoma in nude mice.

Number of mice implanted

51
Number of mice with tumor growth after 4 weeks

$46(90.2 \%)$

The surgical specimen of the patient breast osteosarcoma was minced into fragments of approximately $2 \mathrm{~mm}^{3}$ (Figure 1 ). The fragments were inserted into a subcutaneous pocket made in nude mice. Mice were observed for tumor formation starting on day 14 after implantation. By day 28 , $90.2 \%$ of mice implanted had observable tumor growth.

National Institutes of Health Guide for the Care and Use of Animals under Assurance Number A3873-1. All animal procedures have been previously described (6-13).

Patient-derived tumor. The surgical specimen of a primary osteosarcoma of the breast was obtained under a Kaiser Permanente San Diego Medical Center-approved protocol (IRB\#12617).

Establishment of primary osteosarcoma of the breast PDX nudemouse model. Tumor with surrounding normal tissue was prepared for implantation by mincing the surgical specimen into approximately $2 \mathrm{~mm}^{3}$ fragments (Figure $1 \mathrm{~A}$ and B). Mice were implanted using the method of Hozumi (5). Mice were anesthetized with isoflurane. A $1 \mathrm{~cm}$ skin incision was made at the middle of the back of nude mice. A pocket was created using surgical scissors by dissecting the skin from the dermis. Primary breast osteosarcoma fragments along with surrounding normal tissue were inserted into the pocket (Figure 2A and B). The wound was closed with a 5-0 PDS-II suture (Figure 2C). The implanted tumors were observed for 10 weeks.
Hematoxylin and eosin staining. Fixation, paraffin sectioning, and staining were performed as previously described (7). Hematoxylin and eosin (H\&E) staining was performed according to standard protocols (12).

\section{Results}

Establishment of primary osteosarcoma of the breast PDX model. Fifty-one mice were subcutaneously implanted with patient-derived primary osteosarcoma of the breast fragments along with surrounding normal tissue. Of the 51 mice implanted with primary osteosarcoma of the breast, tumors grew in 46 of them ( $90.2 \%$ establishment) (Table I). Fortysix mice had qualitatively clear growth of tumors within two to four weeks (Figure 3).

Histology of primary osteosarcoma of the breast in the PDX nude-mouse model vs. primary osteosarcoma of the breast 


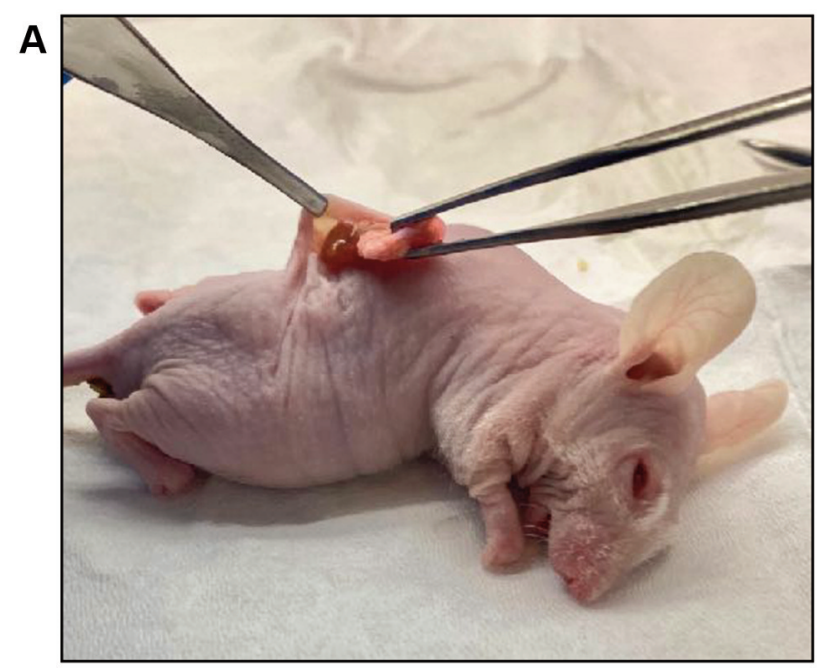

B
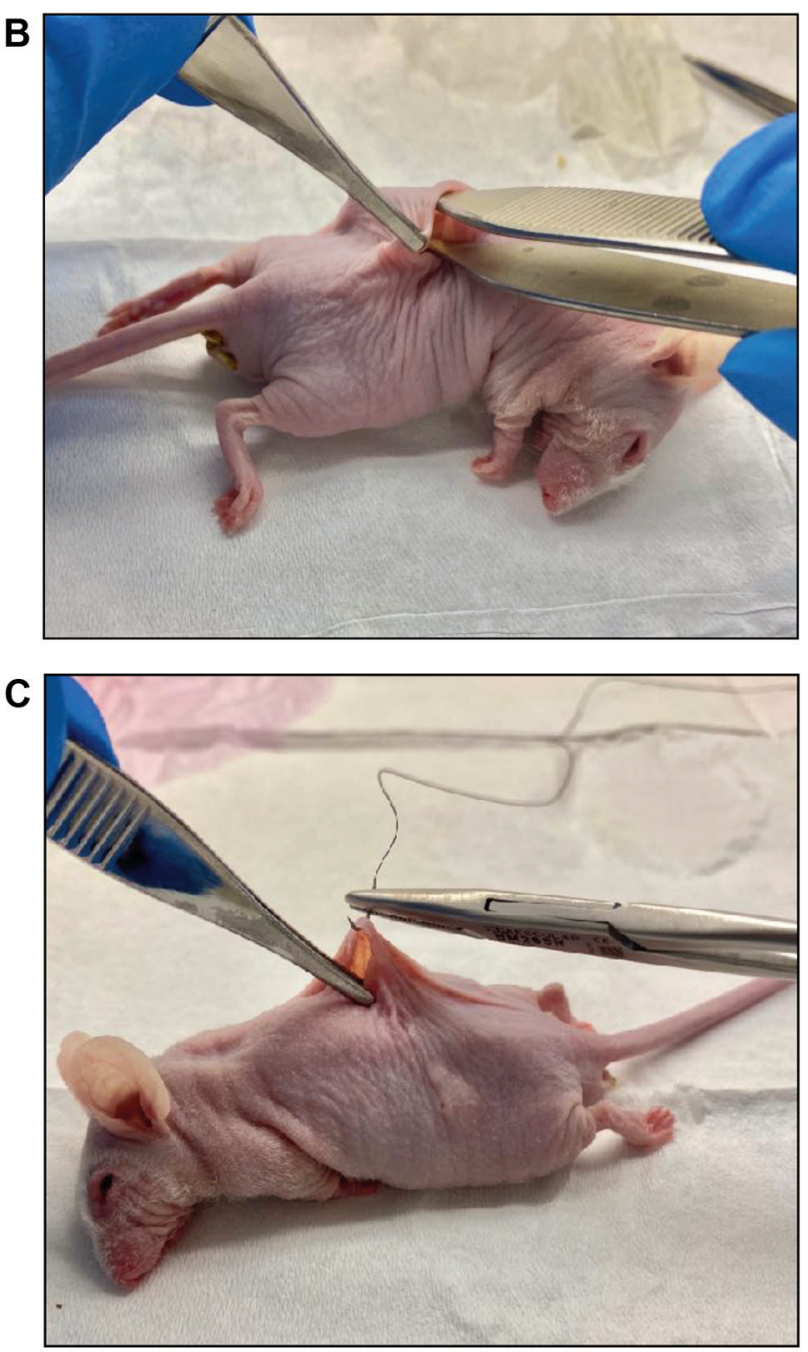

Figure 2. (A) Insertion of tumor fragment and surrounding normal tissue into a subcutaneous pocket on the back of a nude mouse. (B) Pushing tumor fragments into a subcutaneous pocket. (C) A 5.0 nylon suture to close incision.

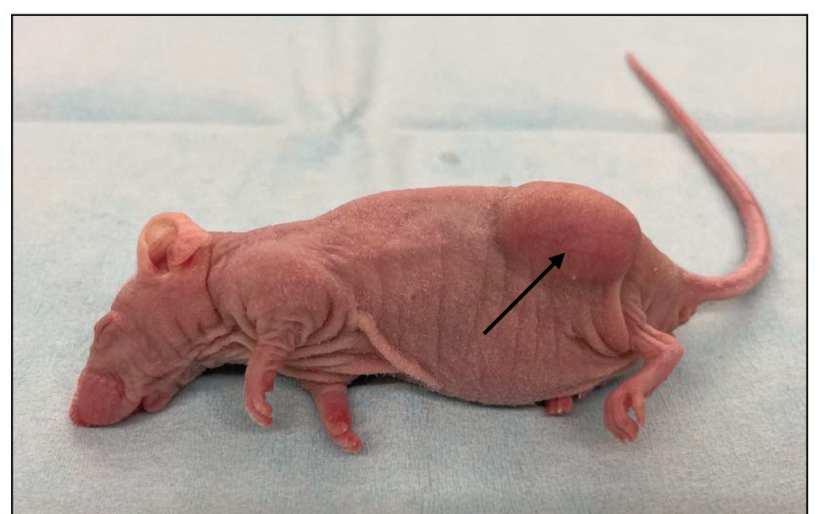

Figure 3. Day 14. Black arrow indicates primary osteosarcoma of the breast growing subcutaneously in a nude mouse.

directly from the patient. $\mathrm{H} \& \mathrm{E}$ staining showed that tumors from the PDX mouse model comprised highly-dense cancer cells with a pleomorphic spindle-shape characteristic of osteosarcoma, very similar to the original patient tumor (Figure 4A and B).

\section{Discussion}

Higher establishment rates for establishing PDX mouse models from patient-derived tumors have been possible using the method of Hozumi, which involves co-implantation of tumor tissue and surrounding normal tissue (5). The present study had a $90.2 \%$ establishment rate with tumors growing in 46 of 51 mice implanted. The inclusion of normal tissue surrounding the tumor tissue seems effective in increasing the establishment frequency (5).

The present study was a successful establishment of the first mouse model of an extremely rare primary osteosarcoma of the breast. Establishment of the primary osteosarcoma in nude mice effectively immortalizes the tumor which can be cryopreserved for future implantation in nude or other immuno-compromized mice. For the first time, it is now possible to do scientific studies on osteosarcoma of the breast due to the successful establishment of the first PDX mouse model of the disease. Future experiments will involve drug-sensitivity screening, as currently there is no identified first-line therapy for osteosarcoma of the breast. Orthotopic models will also be established in order to study metastasis of breast osteosarcoma.

\section{Conflicts of Interest}

The Authors declare that there are no potential conflicts of interest regarding this study. 


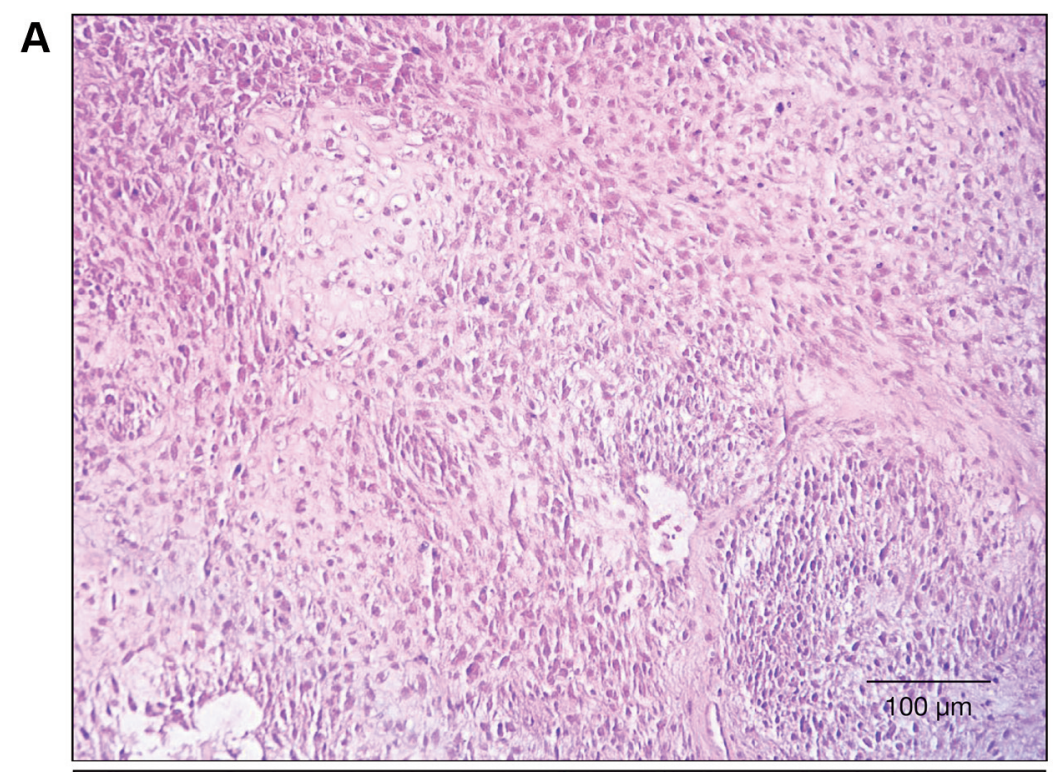

B

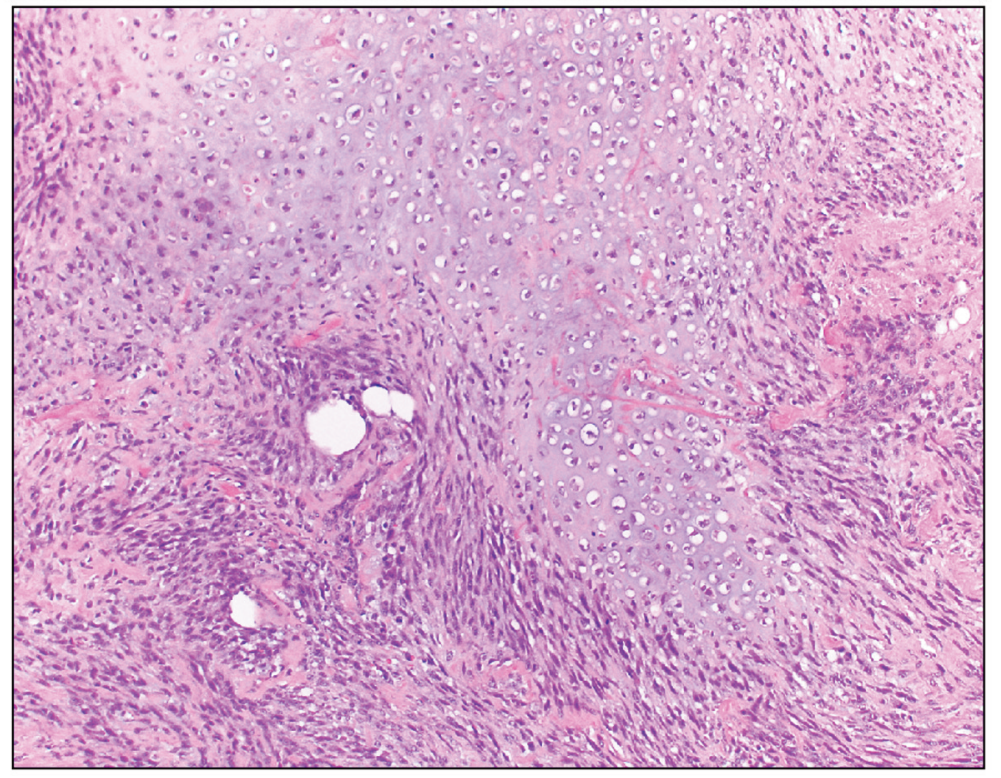

Figure 4. Hematoxylin and eosin (H\&E)-stained osteosarcoma of the breast after four weeks subcutaneous growth as a PDX model in nude mice $(A)$; and tumor directly from the patient $(B)$. Note the high similarity of the spindle-shaped cancer cells in the mouse-grown and original tumor. Scale bar $=100 \mu \mathrm{m}$.

\section{Authors' Contributions}

N.W., J.Y., and R.M.H designed and performed experiments and wrote the paper; J.Y., Y.A., and C.H. gave technical support and conceptual advice. J. W. resected the tumor from the patient. Writing, review, and/or revision of the manuscript: N.W., M.B., and R.M.H.

\section{Acknowledgements}

This paper is dedicated to the memory of A. R. Moossa, M.D., Sun Lee, M.D., Professor Li Jiaxi and Masaki Kitajima, M.D. The present study was funded in part by the Robert M. Hoffman Foundation for Cancer Research, which had no role in the design, execution, interpretation, or writing of the study.

\section{References}

1 Galama R, Matoso J, Capela G, Bôto C, Duarte C and Mendes AR: A rare etiology of a large tumoral mass of the breast - Case report primary leiomyosarcoma and osteosarcoma of the breast. Int J Surg Case Rep 78: 201-203, 2021. PMID: 33360630. DOI: 10.1016/j.ijscr.2020.12.050 
2 Bahrami A, Resetkova E, Ro JY, Ibañez JD and Ayala AG: Primary osteosarcoma of the breast: report of 2 cases. Arch Pathol Lab Med 131(5): 792-795, 2007. PMID: 17488168. DOI: 10.5858/2007-131-792-POOTBR

3 Silver SA and Tavassoli FA: Primary osteogenic sarcoma of the breast: a clinicopathologic analysis of 50 cases. Am J Surg Pathol 22(8): 925-933, 1998. PMID: 9706972. DOI: 10.1097/00000478-199808000-00002

4 Rizzi A, Soregaroli A, Zambelli C, Zorzi F, Mutti S, Codignola C, Bertocchi P and Zaniboni A: Primary osteosarcoma of the breast: a case report. Case Rep Oncol Med 2013: 858705, 2013 PMID: 23691385. DOI: 10.1155/2013/858705

5 Murata T, Hozumi C, Hiroshima Y, Shimoya K, Hongo A, Inubushi S, Tanino $\mathrm{H}$ and Hoffman RM: Co-implantation of tumor and extensive surrounding tissue improved the establishment rate of surgical specimens of human-patient cancer in nude mice: Toward the goal of universal individualized cancer therapy. In Vivo 34(6): 3241-3245, 2020. PMID: 33144429. DOI: 10.21873 /invivo.12160

6 Higuchi T, Miyake K, Oshiro H, Sugisawa N, Yamamoto N, Hayashi K, Kimura H, Miwa S, Igarashi K, Chawla SP, Bouvet M, Singh SR, Tsuchiya H and Hoffman RM: Trabectedin and irinotecan combination regresses a cisplatinum-resistant osteosarcoma in a patient-derived orthotopic xenograft nudemouse model. Biochem Biophys Res Commun 513(2): 326-331, 2019. PMID: 30955860. DOI: 10.1016/j.bbrc.2019.03.191

7 Higuchi T, Oshiro H, Miyake K, Sugisawa N, Han Q, Tan Y, Park J, Zhang Z, Razmjooei S, Yamamoto N, Hayashi K, Kimura H, Miwa S, Igarashi K, Bouvet M, Chawla SP, Singh SR, Tsuchiya $\mathrm{H}$ and Hoffman RM: Oral recombinant methioninase, combined with oral caffeine and injected cisplatinum, overcome cisplatinumresistance and regresses patient-derived orthotopic xenograft model of osteosarcoma. Anticancer Res 39(9): 4653-4657, 2019. PMID: 31519563. DOI: 10.21873/anticanres.13646

8 Higuchi T, Sugisawa N, Miyake K, Oshiro H, Yamamoto N, Hayashi K, Kimura H, Miwa S, Igarashi K, Bouvet M, Singh SR, Tsuchiya $\mathrm{H}$ and Hoffman RM: The combination of olaratumab with doxorubicin and cisplatinum regresses a chemotherapyresistant osteosarcoma in a patient-derived orthotopic xenograft mouse model. Transl Oncol 12(9): 1257-1263, 2019. PMID: 31299622. DOI: 10.1016/j.tranon.2019.06.002
9 Higuchi T, Sugisawa N, Miyake K, Oshiro H, Yamamoto N, Hayashi K, Kimura H, Miwa S, Igarashi K, Chawla SP, Bouvet M, Singh SR, Tsuchiya H and Hoffman RM: Sorafenib and palbociclib combination regresses a cisplatinum-resistant osteosarcoma in a PDOX mouse model. Anticancer Res 39(8): 4079-4084, 2019. PMID: 31366491. DOI: 10.21873/anticanres. 13565

10 Higuchi T, Sugisawa N, Miyake K, Oshiro H, Yamamoto N, Hayashi K, Kimura H, Miwa S, Igarashi K, Kline Z, Belt P, Chawla SP, Bouvet M, Singh SR, Tsuchiya H and Hoffman RM: Combination treatment with sorafenib and everolimus regresses a doxorubicin-resistant osteosarcoma in a PDOX mouse model. Anticancer Res 39(9): 4781-4786, 2019. PMID: 31519579. DOI: 10.21873/anticanres.13662

11 Higuchi T, Sugisawa N, Miyake K, Oshiro H, Yamamoto N, Hayashi K, Kimura H, Miwa S, Igarashi K, Kline Z, Bouvet M, Singh SR, Tsuchiya H and Hoffman RM: Pioglitazone, an agonist of PPAR $\gamma$, reverses doxorubicin-resistance in an osteosarcoma patient-derived orthotopic xenograft model by downregulating Pglycoprotein expression. Biomed Pharmacother 118: 109356, 2019. PMID: 31545293. DOI: 10.1016/j.biopha.2019.109356

12 Higuchi T, Sugisawa N, Yamamoto J, Oshiro H, Han Q, Yamamoto N, Hayashi K, Kimura H, Miwa S, Igarashi K, Tan Y, Kuchipudi S, Bouvet M, Singh SR, Tsuchiya H and Hoffman RM: The combination of oral-recombinant methioninase and azacitidine arrests a chemotherapy-resistant osteosarcoma patient-derived orthotopic xenograft mouse model. Cancer Chemother Pharmacol 85(2): 285-291, 2020. PMID: 31705268. DOI: $10.1007 / \mathrm{s} 00280-019-03986-0$

13 Higuchi T, Yamamoto J, Sugisawa N, Tashiro Y, Nishino H, Yamamoto N, Hayashi K, Kimura H, Miwa S, Igarashi K, Bouvet M, Singh SR, Tsuchiya H and Hoffman RM: PPAR $\gamma$ agonist pioglitazone in combination with cisplatinum arrests a chemotherapy-resistant osteosarcoma PDOX model. Cancer Genomics Proteomics 17(1): 35-40, 2020. PMID: 31882549. DOI: $10.21873 / \operatorname{cgp} .20165$

Received April 30, 2021

Revised May 13, 2021

Accepted May 27, 2021 